sion of the trends in morbidity and mortality from asthma was unable to relate any changes in these to prescription of $\beta_{2}$ agonists, either within a single country or by comparison between countries.

At the end of the meeting an attempt was made to produce some agreed statements. There was general concern that publicising the dangers of $\beta_{2}$ agonists would lead to patients avoiding them. This would create far more dangers than any theoretical problems with regular use as these drugs remain the mainstay of treatment to relieve symptoms in asthma immediately. Most of the worries have surrounded regular use, but the recent guidelines suggest that using inhaled $\beta_{2}$ agonists more than once a day implies the need for regular anti-inflammatory treatment. ${ }^{12}$ This restricts the use of regular bronchodilators to relatively severe cases and shows that most participants had moved away from early prescription of regular $\beta_{2}$ agonists before the recent debate began.

The role of long acting $\beta_{2}$ agonists, such as salmeterol, was also discussed. Their duration of action fits with regular rather than on demand use, and some doctors worry that they will be used prophylactically without concurrent antiinflammatory treatment. Comparative studies with short acting $\beta_{2}$ agonists suggest that they improve control of asthma, ${ }^{13}$ but evidence that they have clinically significant anti-inflammatory activity is lacking. The consensus was that inhaled long acting $\beta_{2}$ agonists should be prescribed only for those already receiving inhaled corticosteroid treatment (the current product licence is only for adults). There was general support for the contents of the guidelines on the treatment of asthma published last year. ${ }^{12}{ }^{14}$

United Medical and Dental Schools,

JOHN REES

Guy's Hospital,

London SE1 9ET

1 Twentyman O, Finnerty JP, Harns A, Palmer.J, Holgate ST. Protection against allergen induced asthma by salmeterol. Lancet 1990;336:1338-42.

2 Lichtenstein LM, Margolis S. Histamine release in vitro: inhibition by catecholamines and methylxanthines. Science 1968;161:902-3.

3 Church MK, Hiroi J. Inhibition of IgE dependent histamine release from human dispersed mast cells by anti-allergic drugs and salbutamol. Br $\mathcal{F}$ Pharmacol 1987;90:421-9.

4 Crane J, Pearce N, Flatt A, Burgess C, Jackson R, Kwong T, et al. Prescribed fenoterol and death from asthma in New Zealand, 1981-83: case-control study. Lancet 1989;i:917-22

5 Pearce N, Grainger J, Atkinson M, Crane J, Burgess C, Culling C, et al. Case control study of prescribed fenoterol and death from asthma in New Zealand, 1977-81. Thorax 1990;45:170-5.

6 Wong CS, Pavord ID, Williams J, Britton JR, Tattersfield AE. Bronchodilator, cardiovascular, and hypokalaenic effects of fenoterol, salbutamol, and terbutaline in asthma. Lancet 1990;336: 1396-9.

7 Kerrehijn KF, van Essen-Zandvliet EEM, Neijens HJ. Effect of long-term treatment with inhaled corticosteroids and beta-agonists on the bronchial responsiveness in children with asthma. $f$ Allergy Clin Immunol 1987;79:653-9.

8 Kraan J, Koeter GH, Mark TW, Sluiter HJ, de Vries K. Changes in bronchial hyperreactivity induced by 4 weeks' treatment with antiasthmatic drugs in patients with allergic asthma: comparison between budesonide and terbutaline. $\mathcal{F}$ Allergy Clin Immunol 1985;76:628-36.

9 Vathanen AS, Knox AJ, Higgins BG, Britton JR, Tattersfield AE. Rebound increase in bronchial responsiveness after treatment with inhaled terbutaline. Lancet 1988;i:554-8.

10 Sears MR, Taylor DR, Print CG, Lake DC, Li Q, Flannery EM, et al. Regular inhaled beta-agonist treatment in bronchial asthma. Lancet 1990;336:1391-6.

11 van Schavck CP, Graafsma SJ, Visch MB, Dompeling E, van Weel C, van Herwaarden CLA Increased bronchial hyperresponsiveness after inhaling salbutamol during 1 year is not caused by Increased bronchial hyperresponsiveness after inhaling salbutamol during
subsensitization to salbutamol. F Allergy Clin Immunol 1990;86:793-800.

12 British Thoracic Society, Research Unit of the Royal College of Physicians of London, King's Fund Centre, National Asthma Campaign. Guidelines for the management of asthma in adults. I Chronic persistent asthma. BMf 1990;301:651-3.

13 Ullman A, Hedner J, Svedmyr N. Inhaled salmeterol and salbutamol in asthmatic patients: an evaluation of asthma symptoms and possible development of tachyphylaxis. Am Rev Respir Dis $1990 ; 142: 571-5$.

14 British Thoracic Society, Research Unit of the Royal College of Physicians of London, King's Fund Centre, National Asthma Campaign. Guidelines for the management of asthma in adults. II. Acute severe asthma. BMF 1990;301:797-9.

\title{
Perinatal bereavement
}

\section{A milestone and some new dangers}

Attitudes to perinatal bereavement have changed profoundly over the past 25 years. Witness the trickle of papers on the topic in the 1960s that has now become a flood (nearly 400 at the last count $t^{\prime}$ ). Another explanation of the increased prominence given to the problem in Britain is the efforts of the Stillbirth and Neonatal Death Society (which began in 1978 as the Stillbirth Association). Started by a few women who had suffered a stillbirth, this organisation now has a network of some 200 self help groups nationally and has helped to change the way professionals manage perinatal bereavement. ${ }^{\star}$ For anyone who may be involved in looking after the bereavedas obstetricians, paediatricians, midwives, or staff on special care baby units - the best place to seek guidance is a booklet published by the society earlier this year. ${ }^{2}$

Perinatal death poses two kinds of problem: firstly, how to manage the immediate painful reactions and, secondly, the serious long term dangers of unresolved parental mourning, which results in psychiatric problems and a vulnerability to future losses and crises. The next pregnancy is a particularly risky time - and is not the panacea that is too often urged. ${ }^{3}$ There is a legacy of personality problems in the remaining children and subsequent "replacement children." Attention now tends to be concentrated too exclusively on the events and grieving at the time, the short term needs of the parents.

The rationale of management is not merely to meet people's need to have doctors and nurses take their pain seriously, important though this is. Management should be designed to help everybody to face up to what has happened rather than to compound bewilderment and guilt by covering things up.
Patients are helped if staff can share in this process and thereby help to initiate mourning. ${ }^{+7}$ It has, therefore, become standard to share information with parents, help them to see and hold their baby, and get photographs and preserve mementos; and, later, to have a proper funeral and a grave for a named child. Psychotherapeutic support should be available, and the obstetric team needs to be attuned to danger signals such as persistent self reproach, marital discord, or an impression of clinging to the loss and to grievances.

Technical advances have created fresh iatrogenic problems by enabling very tiny infants to survive. Families and professional staff are drained and tormented by the emotional and ethical problems that some cases pose. The pendulum is also moving towards another iatrogenic danger with every miscarriage liable to be magnified into a catastrophe, requiring the full panoply of Christian burial to do it justice. There are certainly cases in which exceptional distress caused by a miscarriage requires support and special understanding. Distress may be aggravated if miscarriage is recurrent, if the pregnancy was an older couple's last chance of children, if a bad family history seems to be repeating itself, or if the miscarriage coincides with other bereavements or anniversaries. On the other hand, the overzealous may interfere with the healthy resilience that enables most people to get over an early miscarriage without becoming psychiatrically disturbed.

There is a well meant current tendency to emphasise that grief is unrelated to the duration of a failed pregnancy, ${ }^{8}$ but this is not quite true. Equating early miscarriage with late 
stillbirth may aggravate bewilderment and promote difficulties with mourning. Parents of stillborn infants (uncommon, one in 100 births) should be encouraged to salvage everything they can from the experience and possibly to use spiritual solace if that helps them. By contrast, people should not be pushed into magnifying miscarriage (common, one in three or four pregnancies) into a tragedy. Those who are "thrown" by it require skilled psychotherapeutic help. Formerly, professional staff needed to be made aware of the psychological danger of treating stillbirth as if nothing had happened, but now it needs courage to urge some sense of proportion in very early pregnancy-difficult with such an all or nothing business.

A recent paper discusses the value of counselling for a related problem: middle trimester terminations for fetal abnormality. ${ }^{9}$ Elder and Laurence interviewed women who had received counselling, focusing their inquiries on the grief reactions present six months after the termination. Four fifths experienced acute grief reactions initially and about one in four had unresolved reactions six months later (compared with the findings in a previous series that almost one in two women who had not received counselling had unresolved reactions).

The great unanswered question in all such studies is whether it augurs better for the future if someone is still grieving six months after a loss. Is too much better than too little? The quality of grieving may be more important than the degree of distress: Professional staff need to know when mourning is going wrong and when to refer for psychological or psychiatric support. The superb text produced by the Stillbirth and Neonatal Death Society will help them.

STANFORD BOURNE EMANUEL LEWIS

Consultant Psychotherapists,

Perinatal Bereavement Unit,

Tavistock Clinic,

London NW3 5BA

* The address of the Stillbirth and Neonatal Death Society is 28 Portland Place, London W1N 4DE (tel 071436 5882).

1 Bourne S, Lewis E. Annotated bibliography on the psychological aspects of perinatal death. London Tavistock Clinic, 1991.

2 Stillbirth and Neonatal Death Society. Miscarriage, stillbirth and neonatal death; guidelines for professionals. London: SANDS, 1991.

3 Bourne S, Lewis E. Pregnancy after stillbirth or neonatal death. Lancet 1984;ii:31-3.

4 Klaus MH, Kennell JH. Parent-infant bonding. St Louis: C V Mosby 1982.

5 Lewis E. The management of stillbirth: coping with an unreality. Lancet 1976;ii:619-612.

6 Leon IG. When a baby dies; psychotherapy for pregnancy and newborn loss. New Haven: Yale University Press 1990.

7 Lewis E, Bourne S. Perinatal death. Bailliere's Clin Obstet Gynaecol 1989;3:935-53.

8 When is a fetus a dead baby? [editorial]. Lancet 1991;337:526.

9 Elder $S H$, Laurence KM. The impact of supportive intervention after second trimester termination of pregnancy for fetal abnormality. Prenat Diag 1991;11:47-54.

\section{Keeping confidences in published papers}

\section{Do more to protect patients' rights to anonymity}

A complaint by a patient to the Norwegian patients' ombudsman that she could be identified from a case report in a medical journal prompted Magne Nylenna and Povl Riis, two Scandinavian editors, to survey editors' attitudes to and practices in protecting patients' anonymity (p 1182). ${ }^{1}$ In general they found that editors' good intentions were stronger than their explicit practices. Like many other journals, the $B M \mathcal{F}$ has routinely taken some precautions-banishing patients' initials from case reports, masking their eyes in photographs, occasionally
these may not be enough to Do you recognise this man? removing telling details - but these may not be enough to
deter a determined journalist. Armed simply with the name of the hospital and information from the paper, a journalist may be able to trick further information on patients out of unsuspecting staff. New guidelines issued by the Vancouver Group are intended to offer patients some further protection (p 1194). ${ }^{2}$

Starting from the premise that patients described in clinical papers have a right to anonymity, the guidelines outline some mechanisms for preserving it. Omitting details - for example, occupation - to preserve anonymity may sometimes be acceptable but changing them is not. Omitting information has its risks: occupation or origin may later turn out to be relevant even though it is not thought so at the time (Haitians with AIDS, for example). But falsified data will be taken at face value and may mislead. For clinical photographs we have relied on the convention that masking the eyes in a photograph of a face preserves anonymity. But Slue showed recently what the guidelines point out-that a black bar masks nothing if readers already know the person; it only works if they don't (figure). ${ }^{3}$ The answer in future is to emphasise anonymity but to get consent from the patient if there is still any risk that he or she might be identified, whether from a photograph or a clinical description.

For editors the guidelines suggest that their policies should match their intentions - and that they should publish their policies (we will incorporate the guidelines in our instructions to authors). For authors the guidelines mean that they need to think harder about the details essential to their case descriptions and whether they may inadvertently give away more than they mean to. A conventional description of occupation and geography gives away little for a civil servant in London but a lot for a housepainter in Spitsbergen. When the potentially identifying details might be important authors can protect themselves and their patients by being more ready to gain their patients' consent to describe them or use their photographs.

Deputy editor, $B M \mathcal{F}$

JANE SMITH 1 Nylenna M, Riis P. Identification of patients in medical publications: need for informed consent.
$B M \mathcal{F}$ 1991;302:1182.
2 International Committee of Medical Journal Editors. Statements from the Vancouver Group. $B M \mathcal{F}$
1991;302:1194.

3 Slue WE. Unmasking the lone rider. N Engl f Med 1989;321:550-1. 